\title{
THE EFFECT OF MAGNETIC FIELD ON PERMEABILITY OF EGG SHELLS OF SALMONID FISHES
}

\author{
Marcin SADOWSKI, Aleksander WINNICKI, Krzysztof FORMICKI*, \\ Andrzej SOBOCIŃSKI, and Adam TAŃSKI
}

\author{
Division of Fish Anatomy and Embryology, Agricultural University of Szczecin, Szczecin, Poland
}

Sadowski M., Winnicki A., Formicki K., Sobociński A., Tański A. 2007. The effect of magnetic field on permeability of egg shells of salmonid fishes. Acta Ichthyol. Piscat. 37 (2): 129-135.

Background. The effect of the magnetic field on fish egg shells has not attracted major interest of researchers, even though it could have been predicted that such effect may be vital to fish embryogenesis. One of the hitherto-neglected aspects of the magnetic field action of fish eggs are the changes in the egg shell permeability and possible alteration of the process of embryogenesis. Studying this process and learning the associated phenomena may be important in explaining cases of substantial mortality of the embryos.

Materials and Methods. Fish eggs (Atlantic salmon, Salmo salar L.; sea trout, Salmo trutta L.; and rainbow trout, Oncorhynchus mykiss (Walbaum, 1792) and isolated egg shells, in a custom-made osmometer setups, were subjected to the action of a stable magnetic field $(2 \mathrm{mT})$. The ultrastructure of the egg-shells was studied using a scanning electron microscope (JEOL JSM 6100).

Results. Stable magnetic field ( $2 \mathrm{mT}$ ), affecting fish eggs, caused statistically significant increase in the egg-shell permeability to water, in the period of the egg activation (and also less distinct increase during the entire embryogenesis). Conclusion. Weak, stable magnetic field increases egg-shell permeability to water affecting water management processes in fish eggs, during incubation. This phenomenon may have practical implications for fish hatcheries.

Keywords: magnetic field, egg, egg-shell, permeability, Atlantic salmon, Salmo salar, sea trout, Salmo trutta, rainbow trout, Oncorhynchus mykiss

\section{INTRODUCTION}

The embryos of fishes during their development, between the egg activation and their hatching, are exposed to action of various factors of the external environment. Those factors, while acting simultaneously, may exert higher pressure, than when acting individually. Despite the common assumption about alleged stability of the aquatic environment, its biotic and abiotic factors, affecting aquatic organisms, may be highly diversified. An individual organism is not only affected by selected, uniform environmental factors. Usually the maintenance of homeostasis is dependant on a complex system of a number of external and internal stimuli (Haas et al. 1997)

The magnetic field, and the associated magnetic phenomena are so ubiquitous that they have hitherto been neglected. They attracted some more attention in recent decades and it become evident that living organisms are not indifferent for the action of the magnetic field (Wiltschko and Wiltschko 1995, Kirschvink 1997).

The natural magnetic field of the earth is an integral component of the environment, in the same extent as tem- perature or gravitation, and it also constitutes the background for life processes on the Earth.

The common nature of the magnetic field has prompted many researchers to study in detail its action on living organisms. Wadas (1978) distinguished three basic reasons why magnetic fields affect living organisms: 1) action of non-compensated electron spins, 2) action on liquid crystals, 3 ) effect on positive- and negative charges, being in motion.

To answer the question of the action of the magnetic field on animals, many researchers observed effects of such action. Among the aspects studied was the homing ability of insects (honey bee) (Gould 1980), crustaceans (lobster)(Boles and Lohmann 2003), fishes (salmonids)(Quinn and Brannon 1982), amphibians (newt)(Phillips 1986), reptiles (turtles)(Lohmann et al. 1999), or birds (pidgeon)(Keeton 1971).

The behavioral experiments focused mainly on species performing long-distance migrations, such as eels and salmonid fishes, as well as elasmobranch fishes (Mayer et al. 2005, Nishi et al. 2005).

\footnotetext{
* Correspondence: Prof. dr hab. Krzysztof Formicki, Katedra Anatomii i Embriologii Ryb, Wydział Nauk o Żywności i Rybactwa, Akademia Rolnicza w Szczecinie, ul. Kazimierza Królewicza 4, 71-550 Szczecin, Poland, phone: +4891-423-1061 ext. 262, fax: +4891-423-1347, e-mail: kformicki@fish.ar.szczecin.pl
} 
Another issue targeted by the researchers was the effect of the magnetic field on gametes, embryos, larvae, and adults of different fish species. The aim of those studies has been learning the effects of the field: determining the field levels triggering defined reactions (or their elimination), or explaining mechanisms regulating organism's response to the magnetic field (Formicki 1992, Winnicki et al. 1992, Formicki and Winnicki 1998, Formicki et al. 2004, Tański et al. 2005).

Such broad spectrum of magnetic field effects, prompts the question, whether the magnetic field, through its presence, can alter the permeability of biological membranes, which constitute the most important barrier, protecting developing tissues and organs on an embryo.

The effects of magnetic fields have been studied based on different animal models and individual researchers focus on different aspects of such effects. Hammersbach et al. (1997), in their studies on ciliates, observed that the low-frequency magnetic field positively affected the swimming speed and direction change frequency (depending on the field value). Those authors postulated that the magnetic field might have a direct effect on the mechanism of calcium- and magnesium ion transport, through cell membranes of the ciliates studied.

Vaughan and Weaver (1998), studying molecular changes in biological membranes, subjected to magnetic field, demonstrated that the field might induce formation of pores that would allow molecules and compounds to enter the cell, which would be too big to transfer the membrane barrier at normal conditions. In mammals, the magnetic field affects production of melatonin and some neurotransmitters, calcium contents in the cell, and the pace of cell growth and divisions (Morgan 1989). Wannitikul et al. (1993) confirmed effect of stable magnetic field on mobility of melanin in melanophores of fish.

A number of authors (Hong 1995, Mottrram and Hogan 2002) studied the nature of liquid crystals in biological structures, such as, membranes and membranebound organelles. Under effect of the magnetic field the molecules of liquid crystals arrange themselves along the field lines, which may change parameters of tissues were they are present. The abundance of diamagnetic compounds in biological structures is high (Clement-Metral 1975). Diamagnetic properties of cell membranes translate also into mobility of entire structures, such as erythrocytes under the influence of magnetic field (Takeuchi et al. 1995, Higashi et al. 1997).

Each fish egg consists of egg-shell envelopes, perivitelline fluid, semi-permeable vitelline membrane and yolk. The egg shell determines the shape and appearance of the egg, while the perivitelline fluid-its size. Important findings in fish-egg anatomy and physiology were published by Winnicki (1968). The structure and function of egg-shell envelopes was described in detail by Korzelecka et al. (1998). Recently Patzner et al. (2001), studying ultrastructure of fish egg, discovered pores (other than micropyle) of unknown function.

The aim of the presently described study was to determine whether the magnetic field (and in what extent) could modulate permeability of fish egg shells and if so, what possible changes in the egg shell ultrastructure could be associated with such phenomenon?

\section{MATERIAL AND METHODS}

The experiments were carried out within 2002-2004 in the compound of experimental aquaria and isothermal laboratory of the Division of Fish Anatomy and Embryology, Agricultural University of Szczecin.

The study material were developing eggs of Atlantic salmon, Salmo salar L.; sea trout, Salmo trutta L.; and rainbow trout, Oncorhynchus mykiss (Walbaum, 1792).

The gametes from each specimen of the fish mentioned above were transported separately. The eggs were placed directly in $0.75-\mathrm{L}$ thermoses, while the sperms were held in glass test tubes, which were also placed in thermoses. The thermoses were stacked in isothermal containers with cooling insertions, helping to maintain stable temperature during transport.

Upon the arrival to the laboratory the quality of the eggs and sperms were subjected to a preliminary assessement. The eggs were checked for possible contamination, while the viability (motility) sperms was determined under a microscope, following guidelines of Tomasik (1973). A mixture of eggs, from a number of females, was inseminated with sperm from 3-5 males. The fertilized eggs were incubated in custom-made experimental setups, with constant water flow. The optimum temperatures, needed for incubation of individual fish species, were maintained to the nearest $0.5^{\circ} \mathrm{C}$, in the specifically designed isothermal lab.

Experiment 1. Effect of magnetic field on changes in permeability of egg shells in osmotically active solutions. Custom-made, transparent columns, made of plexiglass cylinders (2-cm diameter; 50 -cm height; $84 \mathrm{~mL}$ volume) were filled with titre solution of sea salt or sacharose. The density of the solution, optimal for eggs of salmon, sea trout, and rainbow trout, amounting to $1.08 \mathrm{~g} \cdot \mathrm{m} \mathrm{L}^{-1}$ were determined with an areometer. The eggs were transferred to these columns and the time of their adjustment to the surrounding water density was measured. (Water escapes from eggs to the hypertonic surroundings and the eggs sink to the bottom of the vessel).

Before the eggs settled down (and were floating in the upper pat of the cylinder), a stable magnetic field was applied in the upper part of the experimental cylinder (at the height of the meniscus). The field was generated by ferrite magnets with expanders an its value amounted to $2 \mathrm{mT}$. The value of the field was measured pointwise inside the column (hallotrone Teslameter HTN-12m, Institute of Telecommunication and Acoustics, Wrocław Technical University. The magnetic field affected the eggs only when they still were in the upper part of the experimental vessel (before started to sink).

The average time of egg sinking was measured and compared with control. The entire setup was affected by the geomagnetic field. 
Experiment 2. Tests for water permeability of live eggs, affected by magnetic field. The experimental setup consisted of glass tube, $2 \mathrm{~mm}$ in diameter, with lower end extended to form a collar. The tube was inserted into a cylindrical cork, intended for regulation of the osmometer position inside the cylinder (Fig. 1). Using a micromanipulator (manufactured by WorldPrec) and blades used in microsurgery, egg shell was removed from a live egg. After the dissection the shell was rinsed in clean water and, with the aid of a silk thread, mounted on the tube's collar. Then the osmometer setup was examined if it was watertight. The osmometer was than filled with $50 \%$ salt solution and placed in a calibrated measuring cylinder, filled with clean water to match the lever of liquid in the osmometer. The time needed for the rise of the liquid level in the osmometer by a single marked unit $(0.05 \mathrm{~mL})$ was measured.

To determine possible effect of the magnetic field on permeability of the egg shell, a stable magnetic field was applied in the place where the egg shell was mounted and the time needed for the liquid level change by one mark was measured.

The experiment was carried out for two fish species only, namely Atlantic salmon and sea trout.

Experiment 3. Searching for possible ultrastructural changes in the egg shell, caused by magnetic field. Fertilized eggs (all from a single female) were incubated at $8^{\circ} \mathrm{C}$. On degree-day 291 (eye spots visible) a stable magnetic field $(2 \mathrm{mT})$ was applied to the eggs. The exposure lasted $2 \mathrm{~h}$ and the eggs ended up in a fixative solution (formalin). They were processed further using standard procedures needed for scanning electron micro- scope and subsequently examined, using JEOL JSM 6100 scanning electron microscope.

The control sample followed the same procedure and it was affected only by the geomagnetic field.

The data acquired were statistically processed using microcomputer software Statistica ${ }^{\circledR} 6.0$ PL. Non-parametric statistics - $\chi^{2}$ tests for values of empiric- and observed differences and the Kolmogorov-Smirnov test for two samples were used to determine the level of significance of differences.

\section{RESULTS}

Experiment 1. Effect of magnetic field on changes in permeability of egg shells in osmotically active solutions. Eggs of selected fish species (salmon, sea trout, and rainbow trout) placed in the column filled with osmotically active solution changed their position with time. Times needed for an egg to travel a defined vertical distance in the column exposed to stable magnetic field were measured and compared with control. The results are shown in Table 1 and on Fig. 2. Live eggs of the three fish species, subjected to magnetic field, sunk towards the bottom faster than in control columns. The differences in descending ranged from 25.6 to 38.7 percentage points. In case of dead eggs, there were no statistical differences in the sinking speed between cylinders with magnets and cylinders without them.

Experiment 2. Tests for water permeability of live eggs, affected by magnetic field. Changes in the height of the water column of the osmometers outfitted with a dissected egg shell, subjected to artificially generated

Sinking time of eggs of individual fish species in columns with osmotically-active solutions $(n=20)$

\begin{tabular}{|c|c|c|c|c|c|c|c|}
\hline & & \multirow{2}{*}{$n$} & \multicolumn{3}{|c|}{ Sinking time [min] } & \multirow{2}{*}{\multicolumn{2}{|c|}{$\begin{array}{c}\text { Difference } \\
\text { Control/MF }\end{array}$}} \\
\hline & & & Minimum & Maximum & $\bar{x}$ & & \\
\hline \multirow{2}{*}{ Rainbow trout } & Control & 20 & 1.52 & 11.41 & 5.47 & \multirow{2}{*}{$37.47 \% *$} & \multirow{2}{*}{$P<0.025$} \\
\hline & MF & 20 & 1.54 & 6.31 & 3.42 & & \\
\hline \multirow{2}{*}{ Salmon } & Control & 20 & 2.36 & 8.27 & 5.54 & \multirow{2}{*}{$25.6 \% *$} & \multirow{2}{*}{$P<0.025$} \\
\hline & MF & 20 & 2.36 & 6.44 & 4.12 & & \\
\hline \multirow{2}{*}{ Sea trout } & control & 20 & 2.13 & 11.54 & 5.34 & \multirow{2}{*}{$38.7 \% *$} & \multirow{2}{*}{$P<0.005$} \\
\hline & $\mathrm{MF}$ & 20 & 1.58 & 5.08 & 3.27 & & \\
\hline
\end{tabular}

* statistically significant differences between magnetic-filed affected eggs and control (Kolmogorov-Smirnov test) MF, magnetic field.

Table 2

Time of changes in the water column level in osmometers

\begin{tabular}{|c|c|c|c|c|c|c|c|}
\hline & & \multirow{2}{*}{$n$} & \multicolumn{3}{|c|}{ Time [min] } & \multirow{2}{*}{\multicolumn{2}{|c|}{$\begin{array}{c}\text { Difference } \\
\text { Control/MF }\end{array}$}} \\
\hline & & & Minimum & Maximum & $\bar{x}$ & & \\
\hline \multirow{2}{*}{ Salmon } & Control & 20 & 294 & 346 & 319.7 & \multirow{2}{*}{$22.67 \% *$} & \multirow{2}{*}{$P<0.001$} \\
\hline & $\mathrm{MF}$ & 20 & 235 & 276 & 247.2 & & \\
\hline \multirow{2}{*}{ Sea trout } & Control & 20 & 314 & 351 & 332.25 & \multirow{2}{*}{$22.87 \% *$} & \multirow{2}{*}{$P<0.001$} \\
\hline & MF & 20 & 241 & 278 & 256.25 & & \\
\hline
\end{tabular}

* statistically significant difference (Kolmogorov-Smirnov test) MF, magnetic field. 


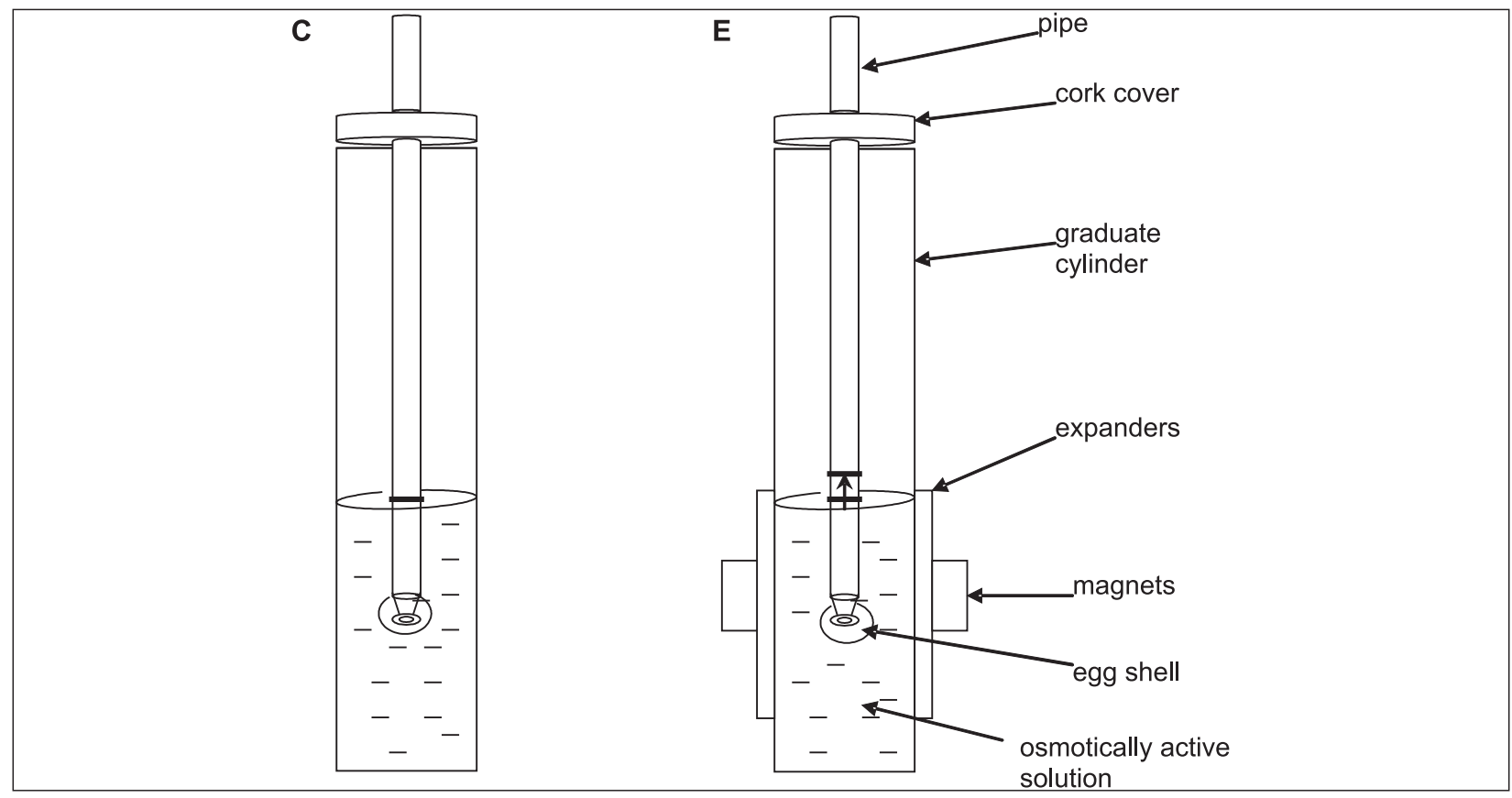

Fig. 1. A diagram of osmometer setups (C, control; E, experimental)
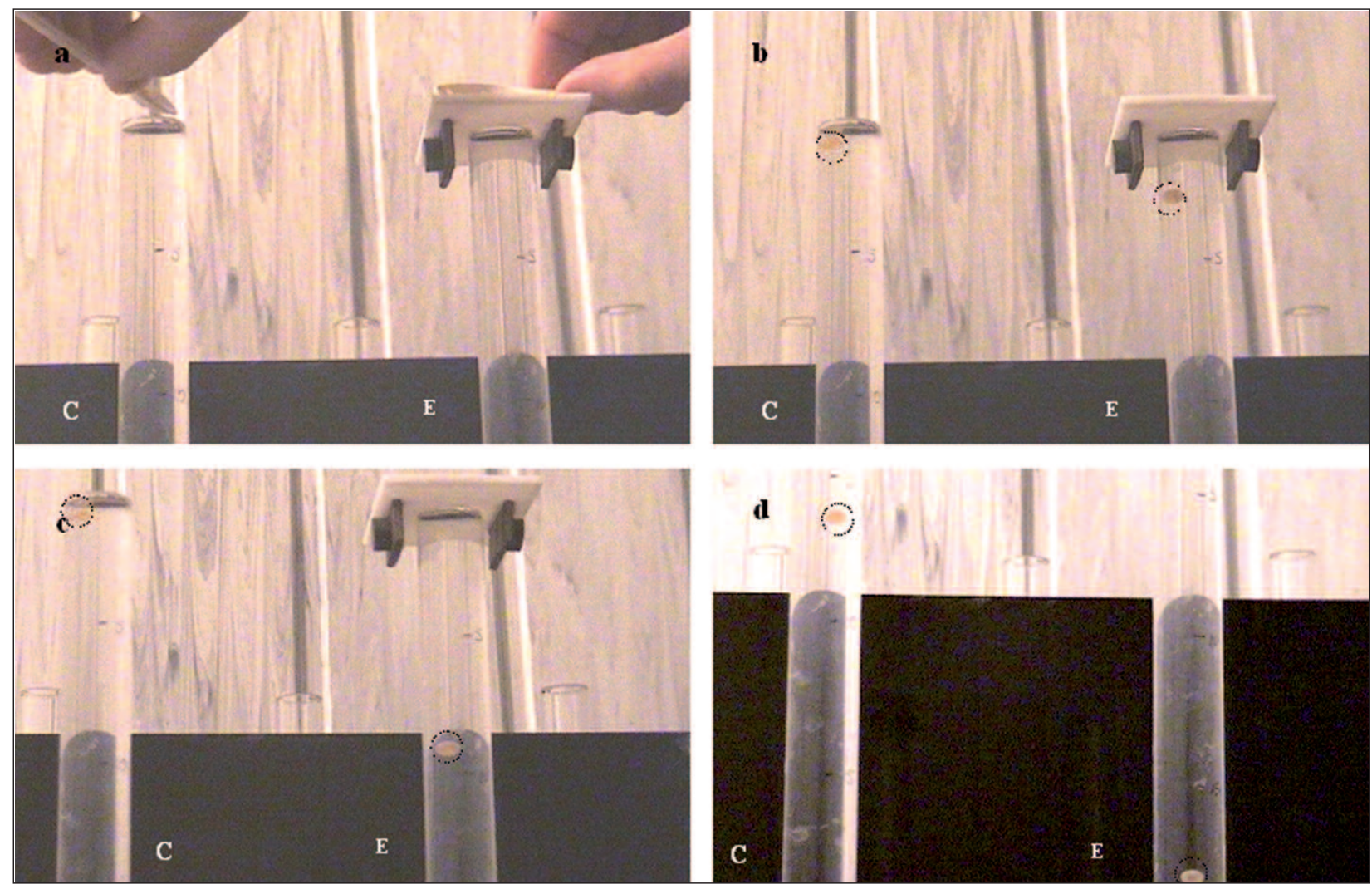

Fig. 2. Egg sinking osmotically active solutions; a - experiment start, b -35 s, c -65 s, d -150 s, C - control, $\mathrm{E}$ - exposed to magnetic field, o position of sinking egg

magnetic field of $2 \mathrm{mT}$, were significantly faster (Table 2) than in control osmometers without magnets.

Experiment 3. Searching for possible ultrastructural changes in the egg shell, caused by magnetic field. SEM micrographs of control samples, taken on magnifica- tions $10000 \times$ revealed clearly visible, well arranged structures around the pores as well as rough inner surface of the shell (Fig. 3). The relevant SEM micrographs of the experimental samples examined, demonstrated that on the inner side of the egg shells subjected to magnetic fields ( $2 \mathrm{mT})$ 
were visible distinct ultrastructural changes (Fig. 3). The overall picture of the inner surface of the shell is blurred, poorly visible, indicating distinct amorphic structure, evidently created during the action of the magnetic field.

\section{DISCUSSION}

Fish eggs, it the form we can observe now, were shaped throughout the evolution and it seems that they perfectly play their role-protection, nourishing, and growth of the embryo, to the point where it will be able to metamorphose and live in the external aquatic environment on its own.

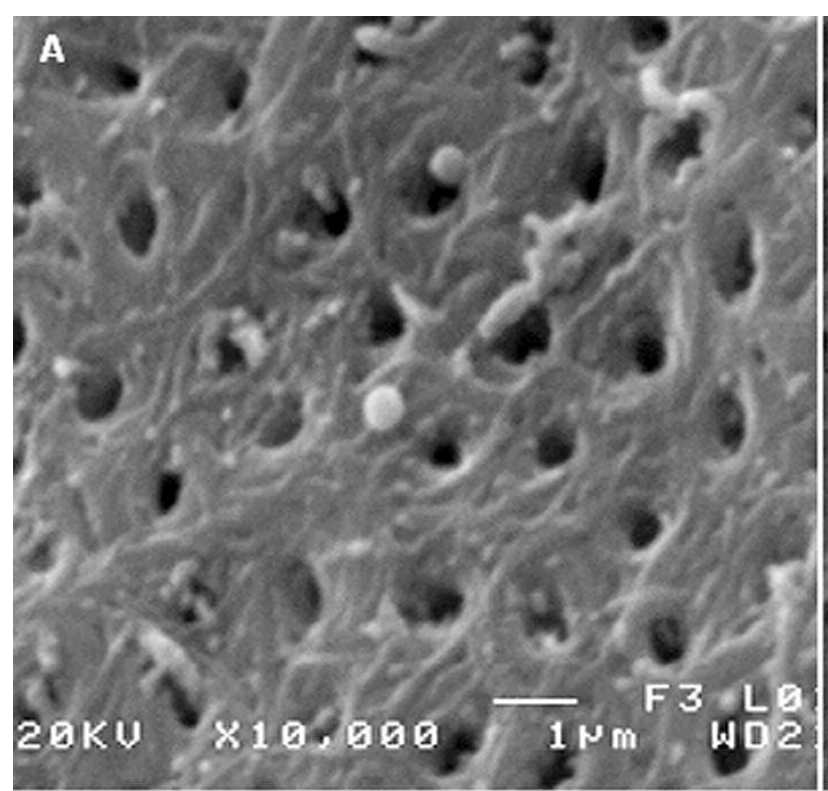

DNA, sex hormones, and nervous system. It is commonly known that after exceeding a defined threshold in the magnetic field value, liquid crystals undergo deformation. The extent and character of such deformation depend on the intensity of the magnetic field, the liquid-crystal phase, and the size of a liquid crystal (Wadas 1978). The most important feature of such deformation is that their final state is different from the initial state. Such deformations of liquid crystals, constituting important constituents of cell membranes, can contribute to changes in their permeability. Similar deformations of nematic liquid crystals were stud-

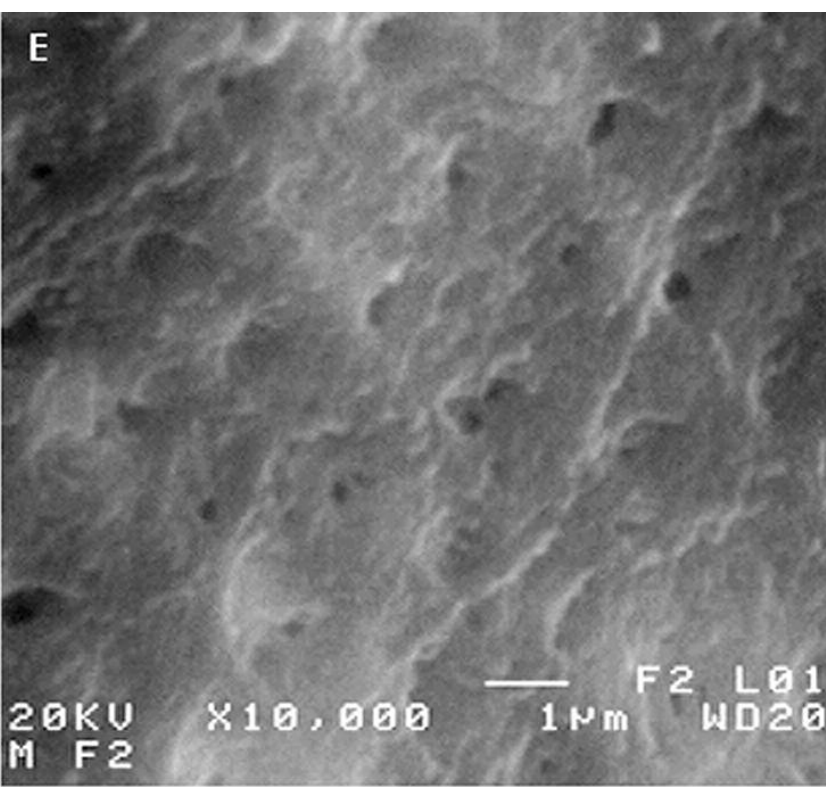

Fig. 3. Inner side of an egg shell of sea trout; A: control; E: affected by magnetic field; magnification and scale bars provided on pictures

The size and shape of an egg are individual traits of each species. The feature, however, they all have in common is the presence of egg shells, constituting a dynamic barrier between the external environment and the embryo. This barrier is not only meant to protect the egg contents against unfavourable actions of the external environment, but their principal role is to manage the water intake by an egg (formation of perivitteline space) and the intake of all substances needed by the embryo.

Searching for clues about possible role of the magnetic field in modifying the permeability of egg shells, we measured the time needed for sinking of an egg in an osmotically active solution. In this process, because of differences in the osmotic pressure, the eggs were loosing water in favour of the surrounding solution, thus increasing their relative density, and sinking towards the bottom. The results obtained, in the presently reported study, suggest that the magnetic field can modify (increase) the water permeability of the egg shell.

Trying to find explanation of the above-mentioned process on molecular lever we focused on a number of issues that might be important for proper explanation of the phenomena observed. One of such issues is the effect of the magnetic field on liquid crystals. They are present in intracellular membranes of the adrenal gland cortex, ovaries, in ied by Mottram and Hogan (2002) using both weak- and strong magnetic fields. They observed that the field may induce changes in the molecular structure of those crystals, causing their defined alignment in relation to the field lines and the surface of the membrane. The extent of the changes is dependant on the value of field used.

Vaughan and Weaver (1998), studying molecular changes in the biological membranes, subjected to both stable- and alternating magnetic field, concluded that the field can cause induction of pores in the membrane. Those pores can enable acquisition by the cell, molecules that could previously not enter the cell. The above authors explain this phenomenon by the interference between the field and the magnetic particles.

It can be also speculated that the membrane contains magnetic particles, which are reciprocally linked by microtubule-like strain with a number of ion channels of the cell membrane. Magnetic particles, through changing their position under influence of the magnetic field, may trigger opening or closing the ion channels (Kirschvink et al. 2001, Walker et al. 2002).

Also polarization of the membrane elements in the magnetic field causes their alignment in relation to the field lines, which may disturb the original structure of the membrane, modifying its selective properties (Hong 1995). 
An interesting question was raised by Verkman (1999). He was interested in possible effect of the magnetic field on aquaporin water channels in the cell membrane. Cutler and Cramb (2002) suggested that aquaporins build water channels in the gill epithelium of eels, enabling transport of water and urea. If indeed aquaporins were sensitive to the magnetic field, it would give us a clue, as to what is the exact mechanism of changes of membrane permeability. No sound proof of this hypothesis has been provided, as yet.

Using dissected egg shells, mounted on an osmometer we demonstrated that fish egg shell are permeable to water. Even though we obtained statistically significant differences in this experiment, one must be cautious about drawing far-fetching conclusions, because a dissected shell, separated from the cell membrane and the perivitteline fluid may show different properties from nature lobes, where such contact has been maintained (Winnicki 1968).

The results of our third experiment was aimed at finding relation between the action of the magnetic field and possible differences in the ultrastructure of the egg shells exposed- and exposed to the field.

SEM micrographs taken et magnifications $3000 \times$ and $10000 \times$ revealed the presence of high number of pores on the internal surface of the egg shell. Gajdušek and Rubcov (1983) examining egg shell of pike, using SEM methods observed numerous pores leading to small canals, featuring sometimes internal flakes. In an unfertilized egg, those canals are open, allowing water in. After the formation of the perivitteline space the canals become gradually clogged by flakes depositing there. The function of the pores and canals on the inner side of egg shell has not been fully explained (Patzner and Glechner 1996, Patzner et al. 2001). According to Hurley and Fisher (1966) they are formed reciprocally between the maternal organism and the oocyte in its last phase of development.

The picture of the inner egg shell, subjected to the magnetic field (before fixation) differs from the picture of an egg, which was not exposed to the field. The pores of the egg shells exposed to the field were smaller and the structure of the canals was disturbed. Control eggs have distinctly pervious canals, while the shells affected by the magnetic field seemed to be filled with some amorphous gel-like substance.

The presence of amorphous structures inside the canals can be a result of the magnetic field action of protein-polysaccharide colloid substances present in the egg shell. Under normal conditions, those substances exhibit highly ordered molecular structure, constituting a barrier for high-size compounds and its those substances that decide about selective properties of the egg shell. Action of a weak stable magnetic field can possibly inflict conformatic changes in the colloid structure, contributing to disruption of their well ordered structure and their precipitation inside shell canals. The gel-like substance, visible inside the canals may be an effect of such precipitation.

Magnetic-field disruption of the efficiently performing shell structure, limiting penetration to the egg, substances contained in the water - may be the reason behind the observed increased permeability of egg shells and in the consequence also changes during the embryogenesis.

\section{REFERENCES}

Boles L.C., Lohmann K.J. 2003. True navigation and magnetic maps in spiny lobsters. Nature 421: 60-63.

Clement-Metral J.D. 1975. Direct observation of the rotation in a constant magnetic field of highly organised lamellar structures. FEBS Letters 50: 257-260.

Cutler C.P., Cramb G. 2002. Branchial expession of an aquaporin 3 (AQP-3) homologue is downregulated in the European eel Anguilla anguilla following seawater acclimation. Journal of Experimental Biology 205: 2643-2651.

Formicki K. 1992. Respiratory movements of trout (Salmo trutta (L.)) larvae during exposure to magnetic field. Acta Ichthyologica et Piscatoria 22 (2): 149-154.

Formicki K., Sadowski M., Tanski A., Korzelecka-Orkisz A., Winnicki A. 2004. Behaviour of trout (Salmo trutta L.) larvae and fry in a constant magnetic field. Journal of Applied Ichthyology 20: 290-294.

Formicki K., Winnicki A. 1998. Reaction of fish embryos and larvae to constant magnetic fields. Italian Journal of Zoology 65 (Suppl.): 479-482.

Gajdušek J., Rubcov V. 1983. Investigations on the microstructure of egg membranes in Pike (Esox lucius). Folia Zoologica 32: 145-152.

Gould J.L., 1980. The case for magnetic sensivity in birds and bees (such as it is). American Scientist 68: 256-267.

Haas C.N., Kersten S.P. Wright K., Frank M.J., Cidambi K. 1997. Generalisation of independent response model for toxic mixtures Chemosphere 34: 699-710.

Hemmersbach R., Becker E., Stockem W. 1997. Influence of extremely low frequency electromagnetic fields on the swimming behavior of ciliates. Bioelectromagnetics 18: 491-498.

Higashi T., Ashida N., Takeuchi T. 1997. Orientation of blood cells in static magnetic field. Physica B 237-238: 616-620.

Hong F.T. 1995. Magnetic fields effect on biomolecules, cells, and living organisms. BioSystems 36: 187-229.

Hurley D.A., Fisher K.C. 1966. The structure and development of the external membrane in young eggs of the brook trout Salvelinus fontinalis (Michill). Canadian Journal of Zoology 44: 173-190.

Keeton W.T., 1971. Magnets interfere with pigeon homing. Proceedings of the National Academy of Sciences of the United States of America 68: 102-106.

Kirschvink J. 1997. Homing in on vertebrates. Nature 390: 339-340.

Kirschvink J.L., Walker M.M., Diebel C.E. 2001. Magnetitebased magnetoreception. Current Opinion in Neurobiology 11: 462-467.

Korzelecka A., Bonisławska M., Winnicki A. 1998. Structure, size and spatial distribution of perch (Perca fluviatilis) egg components during incubation. Electronic Journal of Polish Agricultural Universities, 1, 1, ser. Fisheries (http://www.ejpau. media.pl).

Lohmann K.J., Hester J.T., Lohmann C.M.F. 1999. Long-distance navigation in sea turtles. Ethology Ecology and Evolution 11: 1-23. 
Meyer C.G., Holland K.N., Papastamatiou Y.P. 2005. Sharks can detect changes in the geomagnetic field. Journal of the Royal Society, Interface [electronic resource] / the Royal Society 2 (2): 129-130

Morgan G.M. 1989. Electric and magnetic fields from $60 \mathrm{Hertz}$ electric power: What do we know about possible health risks? Department of Engineering and Public Policy, Carnegie Mellon University.

Mottram N.J., Hogan S.J. 2002. Magnetic field-inducted changes in molecular order in nematic liquid crystals. Continuum Mechanics and Thermodynamics 14: 281-295.

Nishi T., Kawamura G., Sannomiya S. (2005) Anosmic Japanese eel Anguilla japonica can no longer detect magnetic field. Fisheries Science 71: 101-106.

Patzner R.A., Fisher S., Rhiel R. 2001. The eggs of native fishes. 13. River bullhead-Cottus gobio L. 1758 (Cottidae). Österreichs Fischerei 54 (2-3): 50-54.

Patzner R.A., Glechner R. 1996. Attaching structures in eggs of native fishes. Limnologica 26: 179-182.

Phillips J.B. 1986. Magnetic compass orientation in the Estern red - spoted newts (Notophtalamus virdescens). Journal of Comparative Physiology A 158: 103-109.

Quinn T.P., Brannon E.L. 1982. The use of celestial and magnetic cues by orienting sockeye salmon smolts. Journal of Comparative Physiology A 147: 547-552.

Takeuchi T., Mizuno T., Higashi T., Yamagishi A., Date M. 1995 Orientation of red blood cells in high magnetic field. Journal of Magnetism and Magnetic Materials 140-144: 1462-1463.

Tański A., Formicki K., Korzelecka-Orkisz A., Winnicki A. 2005. Spatial orientation of fish embryos in magnetic field. Electronic Journal of Ichthyology 1: 21-34.

Tomasik L. 1973. Specific and individual differences in motility between salmonids spermatozoa. Acta Ichthyologica et Piscatoria 3 (2): 3-14.
Vaughan T.E., Weaver J.C. 1998. Molecular change due to biomagnetic stimulation ad transient magnetic fields: mechanical interference constraints on possible effects by cell membrane pore creation via magnetic particles. Bioelectrochemistry and Bioenergetics 46: 121-128.

Verkman A.S. 1999. Lessons on renal physiology from transgenic mice lacking aquaporin water channels. Journal of the American Society of Nephrology 10: 1126-1135.

Wadas M. 1978. Biomagnetyzm. [Biomagnetism.] PWN, Warszawa. [In Polish.]

Walker M.W., Dennis T.E., Kirschvink J.L. 2002. The magnetic sense and its use in long-distance navigation by animals. Current Opinion in Neurobiology 12: 735-744.

Wannitikul P., Winnicki A., Formicki K. 1993. Effect of constant magnetic field on fish melanophores in vivo and in vitro. In: Blank M. (ed.) Electricity and Magnetism in Biology and Medicine. San Francisco Press, San Francisco: 849-850.

Wiltschko R., Wiltschko W. 1995. Magnetic orientation in animals. Springer Verlag Berlin.

Winnicki A. 1968. Rola i właściwości osłonek jajowych ryb łososiowatych. [The role and characteristics of egg shells of salmonid fishes.] Rozprawa habilitacyjna. [Habilitation (=DSc) thesis.] WSR Olsztyn. [In Polish.]

Winnicki A., Formicki K., Sobociński A. 1992. Water uptake by trout (Salmo trutta (L.)) eggs exposed after activation to magnetic field. Acta Ichthyologica et Piscatoria 22 (2): $155-161$.

Received: 29 October 2007

Accepted: 17 December 2007

Published electronically: 28 December 2007 